\title{
A Look at Informal Logic
}

\author{
Iryna Khomenko
}

Doctor of Philosophical Sciences, Professor, Taras Shevchenko National University of Kyiv

(Kyiv, Ukraine)

E-mail: khomenkoi.ukr1@gmail.com

ORCID: 0000-0003-3522-2271

The challenges of the global time require new solutions and up-to-date ways of thinking and communication. These challenges call for the ability to use critical thinking to face the ever-changing world and the ability to maintain a dialog based on the effective skills of communication. Studies in the fields of logic and argumentation theory are of particular importance in this regard. Nowadays they can be presented as a mix of theoretical and practical approaches.

In this paper, I will present my reflections on informal logic, which was formed in the late 1970s. Unfortunately, in spite of numerous papers, books, and text-books published over the last forty years, consensus on many issues in this field has not been achieved so far. Therefore, it is difficult to treat informal logic as one of the well-defined approaches to argumentation. The goal of this paper is to take a look at the place of informal logic in state-of-the art study of argumentation by clarifying its subject matter and figuring out the realm to which informal logic belongs.

Keywords: logic, informal logic, formal logic, theory of argumentation, epistemology, cognitive science, real argument

Received February 18, 2018; accepted March 16, 2018

Future Human Image, Volume 9, 2018:

DOI: $10.29202 / \mathrm{fhi} / 9 / 5$

\section{Introduction}

The challenges of the globalized world require new solutions and fresh ways of thinking and communication. These challenges call for the ability to study new issues and quick change your mind, the ability to use critical thinking to face the ever-changing world and to maintain a dialog based on the effective communication skills. Studies in the fields of logic and theory of argumentation are of particular importance in this regard.

It should be stated that until the middle of the $20^{\text {th }}$ century, the dominant approach to the study of argumentation was logical, or rather formal-logical one. "Logic was for millennia seen as the skeleton of argument" [Hample, 2006: 2].

(C) Khomenko, Iryna, 2018 
Logic is primarily concerned with reasoning and we can find in numerous text books on logic its definition as the science of reasoning. In order to summarize the traditional view of logic let's look at such quote: "For over two millennia, since the days of Aristotle and Euclid, the notion of formal logic has figured centrally in conceptions of human reasoning, rationality, and adaptiveness. To be adaptive, the story goes, we must be rational about ends and means, truth and evidence. To be rational, we must reason about what means suit what ends, what evidence supports what conclusions. And to so reason, we must respect the canons of logic" [Perkins, 2002: 187].

However, as it turned out, the canons of standard logic had not been sufficient for the analysis of various situations from real life. That is why, in the late $20^{\text {th }}$ century informal treatments appeared in argumentation area. The key reason of their development was the criticism of the possibilities of formal logic. First of all among neoclassical theoretical approaches to argumentation it is necessary to point out Toulmin's concept of the 'working logic' [Toulmin, 1958] and Perelman's treatment of the 'new rhetoric' [Perelman \& Olbrechts-Tyteca, 1958].

Stephen Toulmin believed that the key problem of formal deductive logic is that it reduces arguments, used in different situation, to universal standards even though the procedure must depend on the realm of knowledge in which they are used. In his opinion, it is necessary to create a new logic similar to epistemology, which has broader subject matter including argumentative process in various spheres of human life and primarily in law. In this respect, he identified formal logic as the 'ideal logic' while informal one is the logic which operates or the 'working logic.'

Chaim Perelman believed that rapid development of mathematical logic became the reason why logicians developed mainly the theories of mathematical proof and did not pay attention to the problem of proof in liberal arts. Natural sciences deal with the obvious statements or statements which may be deduced from their combinations. Unlike them, arts deal with the values. Thus, we cannot use the same proof scheme in natural science and liberal arts. In order to highlight this distinction, Perelman used 'proof' for natural science and 'argument' — for humanities. He held the position that formal logic is the 'logic of proof' and informal logic is the 'logic of argument.'

As a result, Stephen Toulmin and Chaim Perelman concluded that most areas of intellectual and practical activities cannot be limited to formal-logical thinking and require a new logic as a theory of argumentation. Following this idea, Stephen Toulmin came up with 'working logic' while Chaim Perelman developed 'new rhetoric.'

The approaches, discussed above, have inspired new interesting developments. It should be stated that nowadays informal studies of argumentation are topic within the scientific community. During the late $20^{\text {th }}$ century and almost the past two decades of the $21^{\text {th }}$ century their results are being actively discussed at the conferences, symposiums, and workshops. ${ }^{1}$

Today a number of different streams can be identified as informal: American tradition of communication studies and rhetoric, linguistic approaches, pragma-dialectics, informal logic, pragmatic approach etc ${ }^{2}$.

\footnotetext{
${ }^{1}$ Among them are well known International Symposium on Informal Logic (Canada); International Conference on Argumentation (Netherlands), European Conference of Argumentation (ECA) and others.

${ }^{2}$ It should be noted that more recently formal approaches in argumentation theory have been further developed too. As examples are formal dialectics and promising connections between approaches in fields of argumentation theory and artificial intelligence.
} 
For my present purposes it is particularly important to take a look at informal logic. It was formed by group of Canadian scholars in the late 1970s, who then called themselves informal logicians. J. Anthony Blair and Ralph H. Johnson from the University of Windsor, Ontario, Canada were first and foremost among them. They "contributed the institutional conditions for the establishment of informal logic as a field of research." [Eemeren et al., 2015: 373].

Unfortunately, in spite of numerous papers, books, and text-books on informal logic, published over the last forty years, consensus on many issues has not been achieved so far. In this regard it is difficult to consider informal logic as one of the well-defined vision of argumentation. Not coincidentally, in Handbook of Argumentation Theory, published in 2015, it was pointed out that the term informal logic cannot refer to one well-delineated approach. "It rather refers to a collection of attempts to develop and theoretically justify a method for the analysis and evaluation of natural language arguments in different context of use that is an alternative to formal logic." [Eemeren et al., 2015, 2015: 374].

In this paper I would like to introduce my vision of informal logic by clarifying its subject matter and figuring out the realm to which informal logic belongs to.

\section{Informal logic versus Formal logic}

I begin with the question: is informal logic related to the area of logic? It is also important for the reason that the term 'informal logic' is still staying controversial and sometimes unacceptable for those who call themselves formal logicians. Researchers have divergent opinions about this problem.

Firstly, one of the responses is that informal logic does not belong to the realm of logic. This viewpoint can be illustrated with Hintikka's quote: "I have a great deal of sympathy with the intensions of those philosophers who speak of 'informal logic,' but I do not think that any clarity is gained by using the term 'logic' for what they are doing" [Hintikka, 1999].

Secondly, logicians believe that informal logic is logic. For example, James B. Freeman thinks: "What is logic? To this, a classic answer is that logic is the appraisal of reasoning or argument.... According to this definition, there is no question that informal logic is logic." [Freeman, 1994: 36].

Yet another view is that informal logic is closer to the discipline studing theoretical and practical problems of argumentation. In this regard Frans Hendrik van Eemeren writes: "the label informal logic covers a collection of normative approaches to the study of reasoning in ordinary language that remain closer to the practice of argumentation than formal logic" [Eemeren, 2009: 117].

This point can be found even in Blair's and Johnson's texts: “informal logic may be seen as a branch of argumentation theory. Put the other way around, any over-all theory of argumentation will need to contain as a component a theory of informal logic" [Johnson \& Blair, 1994: 15].

David Hitchcock claims the following point of view about informal logic: "it might in fact better be called 'theory of argument.' Its questions have however traditionally been regarded as part of logic, broadly conceived. The name can thus be taken to refer to that part of logic as traditionally conceived that is not covered by contemporary formal logic." [Hitchcock, 2007:101].

Summing up what comes from various views we can see that the question whether informal logic belongs to the realm of logic still remains open, unfortunately. 
In order to clarify this problem I am going to compare formal and informal logic. The results we can see in the Table 1.

\section{Table1. Formal and Informal Logics}

\begin{tabular}{|l|l|}
\hline \multicolumn{1}{|c|}{ Formal Logic } & \multicolumn{1}{c|}{ Informal Logic } \\
\hline Normative study of reasoning. & Normative and descriptive study of reasoning. \\
\hline $\begin{array}{l}\text { It develops formal standards, criteria, } \\
\text { procedures. }\end{array}$ & $\begin{array}{l}\text { It develops informal standards, criteria, } \\
\text { procedures. }\end{array}$ \\
\hline $\begin{array}{l}\text { Reasoning is considered as inferential } \\
\text { structure. }\end{array}$ & $\begin{array}{l}\text { Reasoning is considered as a type of dialog, } \\
\text { type of speech act. }\end{array}$ \\
\hline It uses artificial language. & It uses natural language. \\
\hline It identifies logical form of reasoning. & $\begin{array}{l}\text { It identifies structure and scheme of real } \\
\text { argument. }\end{array}$ \\
\hline It uses formal methods. & It uses methods of diagrams. \\
\hline It analyzes microstructure of reasoning. & It analyzes macrostructure of reasoning. \\
\hline It evaluates reasoning as valid/invalid. & It evaluates reasoning as good/bad. \\
\hline Argument evaluation criteria: validity. & $\begin{array}{l}\text { Argument evaluation criteria: acceptability, } \\
\text { relevance, and sufficiency. }\end{array}$ \\
\hline
\end{tabular}

\section{Does Informal logic belong to Epistemology?}

Epistemology is the second realm in which informal logic is being often identified. The key issue which is being actively discussed in the literature is about whether informal logic is a part of epistemology, particularly applied epistemology. Some researchers have given a positive response to this question. Mark E. Battersby, James Freeman, Robert C. Pinto, Harvey Siegal, Mark Weinstein, and others [Battersby, 1989, 2006; Freeman, 1994, 2000; Pinto, 1994; Siegal, 1988a, 1994b; Weinstein, 1994] are among them.

For example, Harvey Siegel says: "The epistemology of informal logic is then a piece with the epistemology of formal logic and that of anything else. It involves spelling out the character of particular informal practice and principles, and making cases for regarding them as valid or invalid, justified or unjustified. These cases must in turn be evaluated in terms of our general theoretical understanding of the strengths and weaknesses of such cases. The project of enhancing that theoretical understanding is a primary strand of epistemology. It is in this sense that the epistemology of informal logic is of piece with epistemology generally" [Siegel, 1994: 136].

This point of view is also supported by Mark E. Battersby: "The term "informal logic" tends to "anchor" the study of arguments in formal logic. Such a nomenclature tempts us to use models of reasoning based on deduction and potentially to miss the actual nature of most reasoning. "Applied epistemology" focuses the discipline towards the actual practice of how people come to and should come to justified beliefs. In an analogy with applied ethics, the study of people's actual epistemological practices can provide both information and challenges for the theoretician of reasoning." [Battersby, 2006: 41].

Another researcher, James Freeman agrees with the previous authors and notes: "informal logic is epistemological. Two central questions concern premise acceptability and connection adequacy. Both may be explicated in terms of justification, a central epistemological concept." [Freeman, 2000: 117]. 
All these points are coming together in the following way. Informal logic can be considered as an applied epistemology in a sense that it is an application of epistemological findings to the evaluation of arguments. It means that epistemological nature of informal logic is directly connected to the problem of argument evaluation.

In this respect, my next step would be to reflect on a question about determining what constitutes a good argument in logic. Unfortunately, no consensus has been reached so far in terms of defining the notion of such argument. Generally, it can be distinguished as two key approaches to the evaluation of the argument: fallacies approach and criteria approach.

Outsiders often link informal logic with the study of informal fallacies, which are not covered by formal logic. However, a lot of informal logicians feel skeptical towards such fallacies approach to the evaluation of arguments. The traditional fallacies (primarily including ad hominem) describe theses argument as perfectly reasonable. In this respect, many informal logicians try to clarify what makes an argumentative move legitimate as well as the conditions under which it is fallacious.

Now let's look at criteria approaches. We covered various way to separate a good argument from a bad one. For instance, speaking of traditional criteria we can talk about 'soundness' and 'validity.'

An argument is good if and only if it is formally valid and its premises are true. It should be noted that 'validity' is a purely logical criterion because we can identify validity of argument by the logical methods. Meanwhile, it is not possible to establish whether its premises and conclusion are true or not.

The fact that by following these criteria all good arguments are being reduced to deductive proves how strong they are. There are obvious counter-examples to the hypothesis that an argument is good if and only if it is sound in this technical sense. We can see that some arguments which we take to be good are not sound by reflecting on examples of perfectly acceptable arguments whose premises are not all true, or whose inferential step is not deductively valid. In this regard the point of view highlighting inadequacy of formal logic to be the tool for evaluating natural-language arguments is wide spread and recognized within informal logic.

In order to avoid such restriction researchers offered another approach to argument evaluation. For example, Charles Leonard Hamblin distinguishes alethic, epistemic, and dialectical criteria for good argument [Hamblin, 1970: 224-252]. Unfortunately, it should be noted that although given points were identified clear definition of good argument has not been provided.

Informal logicians have developed other criteria for assessing arguments. For instance, a triad of acceptability, relevance, and sufficiency is often used as a popular set of criteria in this regard. In order to be considered good premises of an argument must be acceptable, relevant to the conclusion and sufficient to support it. Let's consider these criteria in more details. The main question in this regard is whether informal criteria should be considered as logical or epistemological.

From my point of view, these criteria bring argument appraisal much closer to epistemological approach than to formal logical one. Firstly all of these criteria are explicated via epistemological concepts such as belief, knowledge, common knowledge, justification, and others. For example, one of the standard tests for premises acceptability is whether a premise satisfies the common knowledge condition.

Secondly, informal researchers hold that these criteria are best conceived in a relation to a particular person in at a particular time and in a particular epistemological situation. For 
example, acceptability is relative to the particular evaluator or to the particular audience that decides in an argument is there. This criterion refers not to the fact that the evaluator or audience accepts the premises, but to the fact that it is reasonable for the evaluator or audience to accept the premises, whether or not they in fact do so. Thus, premises can be acceptable to a particular person, even though the person does not really agree with them. Moreover, they can be acceptable even if they are false. Therefore, it is possible that a false premise would be acceptable to someone if that person has good reason to accept it.

Finally, this method does not have a proper logical back up to be used for identifying the goodness of an argument within informal logic. Let us consider relevance criterion. In short, relevance within informal logic is the relation between premises and conclusion of an argument. But the property of the premise to be relevant to its conclusion is called "premissary relevance" or "local probative relevance." This relevance differs from logical relevance which can be defined as a relationship of entailment between a set of propositions.

Many informal logicians attack attempts to interpret relevance as a semantic relation as determined by logic. They try to interpret relevance as a pragmatic notion. In this regard relevance of each premise is not a necessary precondition for a good argument and depends on the particular epistemic situation. It means that a good argument cannot be turned into a bad one by adding an irrelevant premise. In typical cases adding an irrelevant premise to an argument will still leave the argument to be capable of fulfilling its function.

\section{Informal logic and Cognitive science}

At the beginning of my paper I have already noted that during a long time the dominant approach to the study of argumentation was formal-logical. Accordingly real argument may be good only if it are built, based on the canons of logic.

In this respect the question arises: what are these canons of logic? The answer we can found in numerous text books on logic. From a logical point of view, argumentation should be understood as a text with arguments produced by someone and available for logical reconstruction. You start by accepting certain premises; you then accept intermediate conclusions that follow from the premises or earlier intermediate conclusions in accordance with certain logical rules of inference. Let's not forget that in order to be make logical analysis possible, these arguments must be "squeezed" into one or another logical form of reasoning, primarily deductive one. Finally, you end up with accepting new conclusions that you have inferred directly or indirectly from your original premises.

However, traditional view on reasoning poses a challenge as most people in daily life do not argue like that. Over the past 50 years cognitive psychology accumulated a lot of experimental data [Declerck \& Reed, 2001; Evans, 1998; Fiddick et al., 2000; Ford, 1995]. We can see how 'natural deduction' is developing as a new way to look at reasoning. Scholars suggest that reasoning should rely not only on the logical form, but om the mental one as well. They testify to the discrepancy between the logical theory and the practice of reasoning, namely conditional, counterfactual and even syllogistic.

Moving on, let's turn to the examples that confirm the fact that a person in daily life tends to be guided not only by the canons of logic, but by the context, cultural stereotypes, and others things. It should be noted that all of these points relate to human's mental presentation of the world. 
For the purposes of this paper I propose to examine the experimental results called "The Suppression Task". The author of this experiment is Ruth M. Byrne and her results were published in the paper "Suppressing Valid Inferences with Conditionals" [Burne, 1989].

Everybody who has at least some sort of knowledge about formal logic knows one of the most recognizable inference rules - modus ponens. It is often defined as: if A implies B and A holds, we can conclude that B holds.

This poses a question whether this logical inference rule can be mental inference rule at the same time for personal usage in reasoning with conditional sentence?

Ruth M. Byrne begins with reasoning that has the form of modus ponens (Example 1).

Premise 1: If she has an essay to write then she will study late in the library.

Premise 2: She has an essay to write.

Conclusion: She will study late in the library.

As a result, $96 \%$ of subjects conclude that she will study late in the library.

Then Ruth M. Byrne replicated these results by presenting a second condition containing an alternative for the same consequent (Example 2).

Premise 1: If she has an essay to write then she will study late in the library.

Premise 2: She has an essay to write.

Premise 3: If she has a textbook to read she will study late in the library.

Conclusion: She will study late in the library.

She gets the same result. $96 \%$ of subjects chose the conclusion: She will study late in the library.

Further Ruth M. Byrne extends the experiment by introducing a second condition with an additional requirement that must also hold (Example 3).

Premise 1: If she has an essay to write then she will study late in the library.

Premise 2: She has an essay to write.

Premise 3: If the library stays open she will study late in the library.

Conclusion: She will study late in the library.

Now only $38 \%$ of subjects made modus ponens inferences, compared to $96 \%$ when a simple conditional or two conditionals with alternative conditions were presented.

Ruth M. Byrne concludes that either there are no mental rules for the valid inferences, or that "...suppression by itself tells us nothing about the existence or non-existence of rules of inference in the mind." [Byrne, 1989: 76]

She admits that the results can still be explained in terms of mental rules if one assumes that the joint representation of both sentences makes the application of inference rules impossible. Her proposal is that: "Formal theories, therefore, need to be supplemented with a detailed account of the process of interpretation, because premises of the same apparent logical form are represented in different ways depending on their meaning." [Byrne, 1989: 77]

Later on, she rejects mental rules in favor of the mental model theory. 
Based the aforesaid, I believe that the study of mental (informal) schemes of reasoning that isn't based on the deductive logical forms and rules, but mental presentation or mental picture of world may be a relevant task for informal logicians.

\section{What is Informal logic?}

We have already considered many interpretations of what informal logic is and its interrelations with various fields. Now it is time to define what informal logic actually is.

On my mind, informal logic is best considered as a study of real argument which includes development of certain standards, criteria, and procedures for its interpretation and evaluation. I use the term 'real argument' because informal logicians focus solely on this kind of reasoning. Thus, it can be claimed that such argument is a subject matter of informal logic.

In this regard some questions immediately arise: what are real arguments, what are their key features, what are the distinctions between terms 'reasoning' and 'real argument'? Let's try to answer these questions.

In spite of numerous papers, books, and textbooks published over the last years, it is disappointing that consensus as to what a real argument is has not been achieved yet. The only agreement is that argumentation theorists unite around the point that a real argument is a type of reasoning which is not a subject matter of formal logic.

A quick inspection of reasoning types by various theorists shows that the main differentiation is drawn between deductive and inductive reasoning. Several researchers add the third type abductive reasoning. Thereby the question arises: could these instances of logical reasoning be considered as types of real argument?

Firstly, if the answer is 'yes', then how should we relate to the general idea of informal logic that key feature of a real argument is that it is not a subject matter of formal logic. This point could be illustrated with Johnson's quote about the formal logic gap as: [...] virtual disappearance from the mandate of logic of the focus on real argument." [Johnson, 2000: 105].

Trudi Govier also part companies with Johnson's claims: [...] what should be obvious: that the understanding of natural arguments requires substantive knowledge and insight not captures in the rules of axiomatized systems [Govier, 1987: 204].

Secondly, the answer is 'no', then it is unclear what types of reasoning represent a notion 'real argument'.

In my view, when answering this question it is important to draw a distinction between logical reasoning and real arguments. The distinction is based on the formal and informal understanding of the notion 'reasoning'.

In general, reasoning is presented as an activity of human mind or as a special kind of thinking, interrelation of thoughts. Speaking of the formal understanding, reasoning can be defined as a system, composed of premises and conclusion. Certain thought (conclusion) is based on others (premises) or derive from others. We can distinguish various types of reasoning taking into account logical forms. In this sense scholars distinguish the following types of logical reasoning: deductive, inductive and abductive.

By now we have witnessed many attempts to produce a definition of real argument. However, in my view, none of them is clear enough. Let's try to clarify the term 'real argument'.

First, it should be pointed out that researchers use various labels for this term in informal studies. Here are some of them: real, natural, every day, actual, real-life, ordinary, mundane, marketplace argument. 
For example, according to Blair and Johnson, real argument is an "actual natural language arguments used in public discourse, clothed in their native ambiguity, vagueness and incompleteness. [...] arguments that have actually been used to try to persuade people, the sorts of arguments the student will encounter outside the classroom." [Johnson \& Blair 1994: 6].

Leo Groarke thinks that real arguments are "the arguments found in discussion, debate and disagreement as they manifest themselves in daily life." [Groarke, 2017].

With regard to clarifying this term I consider it as a complex kind of reasoning, which is used in argumentation as a form of dialogical interaction, where arguers aim is to resolve a conflict of opinions expressed by verbal means.

In my view, we can highlight the key features of such arguments and it can be described in the following way.

(1) Unlike formal logic, which uses artificial language, real argument is expressed by natural language.

(2) Real argument is a dialogical argument. Arguing requires at least two arguers. They express to divergent points of view on certain question and at the same time should keep in mind objections, which they may have.

(3) Real argument relates to everyday communication. In this regard the artificial reasoning from logic textbooks are not relevant to real arguments.

(4) Real argument mostly is a defeasible argument. We can see that some arguments, which we consider to be good, are not sound by reflecting on examples of perfectly acceptable arguments whose premises are not all true, or whose inferential step is not deductively valid.

(5) One of the key features of real argument is its incompleteness. Arguers often do not use all premises and conclusions in such arguments. Some of them do it on purpose to confusing the opponents, but sometimes this case occurs when arguers do not have sufficient skills to express their thoughts clearly.

(6) Real argument depends on the context of utterance.

In addition, I would like to emphasize that informal logic cannot be viewed only as a branch of logic. From my point of view, it would be more reasonable to define it as a discipline that sits on the borderline between the interests of logic, epistemology, and cognitive science.

Three perspectives in study of real argument within informal logic can be suggested: logical, epistemic, and cognitive. The first relates to the normative standards, criteria, and procedures of real arguments interpretation. The issues concerning with construction and reconstruction, schemes and forms, unexpressed premises of real argument and others could be considered there.

The epistemic perspective focuses on studying the assessment of a real argument. The cognitive perspective concentrates on a descriptive study of argument, because empirical investigations are important as theoretical ones are in this area. Of the latter, survey data collection is especially noteworthy.

Thus, in my opinion, informal logic should be considered as a normative and descriptive discipline sitting on the borderline between the interests of logic, epistemology, and cognitive science, with a task to study the real arguments through the development of certain standards, criteria, and procedures for its interpretation and evaluation. 


\section{Conclusions}

In this paper I try to present my reflections on informal logic as one of the informal streams in state-of-the art study of argumentation. In conclusion, I would like to summarize the main points of my paper.

The appearance of informal investigations in argumentation field was preceded by the publication of two books: The Uses of argument [Toulmin, 1958] and Traité de L'argumentation: La Nouvelle Rhétorique [Perelman \& Olbrechts-Tyteca, 1958]. In my view Toulmin's concept of the "working logic" and Perelman's concept of the "new rhetoric" can be identified as the preconditions of informal research in modern theory of argumentation.

By considering various approaches I set the goal to identify the place of informal logic in state-of-the art study of argumentation. In this way I want to create an adequate basis for providing a precise definition of informal logic. In my view, a suitable definition clarifying a subject matter of informal logic and identifying the realm to which informal logic belongs.

To answer the first question, real argument is the subject matter of informal logic. It is as a complex kind of reasoning, which is used in argumentation as a form of dialogical interaction, where arguers aim is to resolve a conflict of opinions expressed by verbal means.

Next, it is important to highlight, the key features of such argument: (i) it is expressed in natural language; (ii) it is a dialogical argument; (iii) it relates to everyday communication; (iv) it mostly is a defeasible argument; (v) incompleteness remains one of the key features of a real argument; (vi) it depends on the context of utterance.

Furthermore, I emphasize that a real argument can be studied within informal logic from various perspectives: logical, epistemic and cognitive. The first relates to the normative standards, criteria, and procedures of interpreting real arguments. The second focuses on the problem of real argument assessment. The third concentrates on a descriptive study of argument. On my mind, informal logic involves appeals not only to the theoretical studies. Empirical research is important in this area as well.

Recapitulating, I can now propose a definition of informal logic, which is based on the one proposed by Ralf H. Johnson and J. Antony Blair [Johnson \& Blair, 2000] ${ }^{3}$. It clarifies and broadens our vision of informal logic and its place in contemporary study of argumentation. Here it is: informal logic can be viewed as a normative and descriptive discipline, sitting on the borderline between the interests of logic, epistemology, and cognitive science, with a task to study the real arguments through development of certain standards, criteria, and procedures for its interpretation and evaluation.

\section{References}

Battersby, Mark E. Applied Epistemology and Argumentation Epidemiology. Informal Logic, 26(1), 2006: 41-62.

Battersby, Mark E. Critical Thinking as Applied Epistemology: Relocating Critical Thinking in the Philosophical Landscape. Informal Logic, 11(2), 1989: 91-100.

Byrne, Ruth M..Suppressing valid inferences with conditionals. Cognition, 31,1989: 61-83.

Declerck, Renaat., \& Reed, Susan. Conditionals: a comprehensive empirical analysis. Mouton de Gruyter, 2001.

3 "Informal logic designates that branch of logic whose task is to develop non-formal ${ }_{2}$ standards, criteria, procedures for analysis, interpretation, evaluation, critique and construction of argumentation in everyday language.” [Johnson \& Blair, 2000: 102] 
Eemeren, Frans Hendrik van. The Study of Argumentation. The SAGE Handbook of Rhetorical Studies. SAGE, 2009: 109-24.

Eemeren,Frans. Hendrik van, Garssen, Bart, Krabbe, Erik C. W., Snoeck Henkemans, Francisca A., Verheij, Bart,

Wagemans, Jean H. M. eds. Handbook of argumentation theory. Dordrecht: Springer Reference, 2015.

Evans, Jonathan. Matching bias in conditional reasoning: Do we understand it after 25 years? Thinking and Reasoning, 4, 1998: 45-82.

Fiddick, Laurence., Cosmides, Leda, and Tooby, John. No interpretation without representation: the role of domain-specific representations and inferences in the Wason selection task. Cognition, 77, 2000: 1-79.

Ford, Mark. Two modes of mental representation and problem solution in syllogistic reasoning, Cognition, 54, 1995: 1-71.

Freeman, James B. The Place of Informal Logic in Logic. New Essays in Informal Logic. Winsdor, Ontario, Canada: Informal Logic, 1994: 36-47.

Freeman, James B. The Place of Informal Logic in Philosophy. Informal Logic 20 (2), 2000:117-28.

Govier, Trudy. Problems in argument analysis and evaluation. Dordrecht-Holland: Foris Publications, 1987.

Groarke, Leo. Informal logic. In Stanford Encyclopedia on Philosophy, 2017. http://plato. stanford.edu/ entries/logic-informal/ [accessed $2^{\text {nd }}$ January 2017].

Hamblin, Charles Leonard. Fallacies. New York: Methuen, 1970.

Hample, David. Arguing: Exchanging reasons face to face, Routledge, 2006.

Hitchcock, David. Informal Logic and Concept of Argument. Handbook of the Philosophy of Science. Vol. 5. Philosophy of Logic. Amsterdam: Elsevier, 2007.

Hintikka, Jaakko. True and False Logics of Scientific Discovery. Selected Papers. Vol. 5. Dordrecht and Boston: Kluwer, 1999: 115-196.

Johnson, Ralf H. Manifest Rationality. Mahwah, NJ: Lawrence Erlbaum and Associates, 2000. Johnson, Ralf H., and Blair, J. Antony Informal logic. An Overview. Informal Logic, 20 (2), 2000: 93-107.

Johnson, Ralf H., and Blair, J. Antony. Informal logic: past and present. New essays in informal logic. Winsdor, Ontario, Canada: Informal Logic, 1994: 1-19.

Perelman, Chaim and Lucy Olbrechts-Tyteca. Traité De L'argumentation: La Nouvelle Rhétorique. Paris: Presses Universitaires de France La Nouvelle Rhetorique, 1958.

Pinto, Robert C. (1994) Logic, Epistemology and Argumeny Appraisal. New Essays in Informal Logic. Winsdor, Ontario, Canada:Informal Logic, 1994:116-124.

Perkins, David N. Standard Logic as a Model of Reasoning: The Empirical Critique. Handbook of the Logic of Argument and Inference. The Turn Towards the Practical. Amsterdam: Elsevier, 2002: 187-224.

Siegel, Harvey. Educating Reason: Rationality, Critical Thinking and Education. New York: Routledge, 1988.

Siegal, Harvey. (1994b). Justification by Balance and the Epistemology of Informal Logic. New Essays in Informal Logic. Winsdor, Ontario, Canada:Informal Logic, 1994:125-139.

Toulmin, Stephen E. The Uses of Argument. Cambridge: Cambridge UP, 1958.

Weinstein, Mark. Informal Logic and Applied Epistemology. New Essays in Informal Logic. Winsdor, Ontario, Canada: Informal Logic, 1994:140-161. 